Open Systems \& Information Dynamics Vol. 23, No. 4 (2016) 1699001 (2 pages)

DOI: $10.1142 / \mathrm{S} 1230161216990018$

(C) World Scientific Publishing Company

\title{
Index of Vol. 23 (2016)
}

Accardi L., A. Khrennikov, M. Ohya, Y. Tanaka, and I. Yamato, Application of Non-Kolmogorovian Probability and Quantum Adaptive Dynamics to Unconscious Inference in Visual Perception Process

1650011

Accardi L., AB. Dhahri, And Am. Dhahri, Characterization of Product Probability Measures on $\mathbb{R}^{d}$ in Terms of Their Orthogonal Polynomials

AcCardi L., A. JamioŁkowski, And M. Michalski, Masanori Ohya, 1947 - 2016

1677001

Auday M., see Iglesias R., F. Tohmé, And M. Auday

1650012

Caban P., A. Molenda, And K. Trzcińska, Activation of the Violation of Svetlichny Inequality for a Broad Class of States

1650018

Cong S., see Wen J. AND S. CONG

1650005

Czerwiński A. And A. Jamiołkowski, Dynamic Quantum Tomography Model for Phase-Damping Channels

1650019

Da̧Browska A. And J. Gough, Quantum Trajectories for Squeezed Input Processes: Explicit Solutions

1650004

De Raedt H. And K. Michielsen, Computer Simulation of Einstein-Podolsky-

Rosen-Bohm Experiments

1650010

Dhahri Ab., see Accardi L., Ab. Dhahri, And Am. Dhahri

1650022

Dhahri Am., see Accardi L., Ab. Dhahri, And Am. Dhahri

1650022

Gough J., see Da̧Browska A. And J. Gough

1650004

Iglesias R., F. Tohmé, And M. Auday, Contextuality Scenarios Arising from Networks of Stochastic Processes

1650012

IsAR A., Entanglement Generation in Two-Mode Gaussian Systems in a Thermal Environment

1650007

Jamiołkowski A., see Pastuszak G., T. Kamizawa, and A. Jamiołkowski

1650003

Jamiołkowski A., see Czerwiński A. And A. JamioŁkowski

1650019

Jamiołkowski A., see AcCARdi L., A. JamioŁkowski, And M. Michalski

1677001

Joshi R. And S. Kumar, $(R, S)$-Norm Information Measure and A Relation between Coding and Questionnaire Theory

1650015

Kamizawa T., see Pastuszak G., T. Kamizawa, and A. Jamiołkowski

1650003

Kaszlikowski D., see Thompson J., P. Kurzyński, S.-Y. Lee, A. SoedA, AND D. KASZLIKOWSKI

1650009

Khrennikov A., Bell Could Become the Copernicus of Probability

1650008

Khrennikov A., see Accardi L., A. Khrennikov, M. Ohya, Y. TAnaka, And I. YAMATO

1650011

Kumar S., see Joshi R. And S. Kumar

1650015

Kurzyński P., see Thompson J., P. Kurzyński, S.-Y. Lee, A. Soeda, And D. KASZLIKOWSKI 
Author Index

Lee S.-Y., see Thompson J., P. Kurzyński, S.-Y. LeE, A. Soeda, And D. KASZLIKOWSKI

Li Z. And X. Zhang, Nonadditive Topological Pressure of Proper Systems

1650017

LiU F., see Sun J., S. F. LU AND F. LiU

1650016

Lu S. F., see Sun J., S. F. Lu And F. LiU

1650016

Łuczak A., Wigner-Araki-Yanase Theorem in General Theory of Quantum Measurement

1650013

Maciejewski A.J., see Musumbu D.P., M. Przybylska, And A. J. MACIEJEWSKI

1650002

Michalski M., see Accardi L., A. Jamiołkowski, And M. Michalski

1677001

Michielsen K., see De Raedt H. And K. Michielsen

1650010

Militello B., Competition of Continuous and Projective Measurements in Filtering Processes

1650021

Miller M. And R. Olkiewicz, Extremal Positive Maps on $M_{3}(\mathbb{C})$ and Idempotent Matrices

1650001

Molenda A., see Caban P., A. Molenda, and K. Trzcińska

1650018

Musumbu D. P., M. Przybylska, And A. J. Maciejewski, Thermalization in Many-Particle Quantum Walks

1650002

Ohya M., see Accardi L., A. Khrennikov, M. OhyA, Y. TANakA, And I. YAMATO

1650011

Olkiewicz R., see Miller M. And R. Olkiewicz

1650001

Ostrowski M., Quantum Simulation of Two Interacting Schrödinger Particles

1650020

Pastuszak G., T. Kamizawa, and A. Jamiołkowski, On a Criterion for Simultaneous Block-Diagonalization of Normal Matrices

1650003

Pollard B.S., A Second Law for Open Markov Processes

1650006

Przybylska M., see Musumbu D. P., M. Przybylska, and A. J. Maciejewski

1650002

Roga W., see Smaczyński M., W. Roga, And K. Życzkowski

1650014

Smaczyński M., W. RogA, And K. Życzkowski, Selfcomplementary Quantum Channels

1650014

Soeda A., see Thompson J., P. Kurzyński, S.-Y. Lee, A. Soeda, And D. KASZLIKOWSKI

1650009

Sun J., S. F. Lu And F. LiU, On the General Class of Models of Adiabatic Evolution

1650016

Tanaka Y., see Accardi L., A. Khrennikov, M. Ohya, Y. Tanaka, And I. YAMATO

1650011

Thompson J., P. Kurzyński, S.-Y. Lee, A. Soeda, and D. Kaszlikowski, Recent Advances in Contextuality Tests

1650009

Tohmé F., see Iglesias R., F. Tohmé, And M. Auday

1650012

Trzcińska K., see CABAn P., A. Molenda, And K. Trzcińska

1650018

Wen J. And S. Cong, Preparation of Quantum Gates for Open Quantum Systems by Lyapunov Control Method

1650005

Yamato I., see Accardi L., A. Khrennikov, M. OhyA, Y. TAnakA, And I. YAMATO

1650011

ZHANG X., see Li Z. AND X. ZHANG

1650017

Życzkowski K., see Smaczyński M., W. Roga, And K. ŻycZkowski

1650014 